\title{
Qualidade da maçã cv. Gala tratada com 1-metilciclopropeno
}

\author{
Quality of apples cv. Gala treated with 1-methylcyclopropene
}

\author{
Auri Brackmann ${ }^{1}$ Ivan Sestari ${ }^{2}$ Cristiano André Steffens $^{3}$ \\ Ricardo Fabiano Hettwer Giehl ${ }^{4}$
}

\section{RESUMO}

\begin{abstract}
O objetivo deste trabalho foi avaliar a eficiência da aplicação inicial de 1-metilciclopropeno (1-MCP) e o efeito de diferentes doses na reaplicação após quatro meses de armazenamento refrigerado, na manutenção da qualidade de maçãs cultivar Gala. O delineamento experimental utilizado foi o inteiramente casualizado com quatro repetições e unidade experimental composta por 25 frutos. Os tratamentos originaramse da combinação entre o momento da aplicação (início do armazenamento e após 4 meses de armazenamento) e doses de 1 $\operatorname{MCP}\left(0,312,625 n L L^{-1}\right)$. Os tratamentos de 1-MCP foram: $0+O n L L^{-1} ; 0+312 n L L^{-1} ; 0+625 n L L^{-1} ; 625+0 n L L^{-1} ; 625+312 n L L$ ${ }^{1}$ e $625+625 n L L^{-1}$. Após 180 dias de armazenamento a $0,5^{\circ} \mathrm{C}$ mais 14 dias a $20^{\circ} \mathrm{C}$, a aplicação inicial de $625 n L L^{-1}$ de $1-M C P$ proporcionou frutos com maior firmeza de polpa e acidez titulável e manteve os frutos mais verdes, porém não apresentando efeito sobre a ocorrência de podridões e sólidos solúveis totais. A reaplicação de 1-MCP, aos quatro meses de armazenamento, não apresentou efeito na manutenção da qualidade dos frutos. Após 14 dias de exposição dos frutos a $20^{\circ} \mathrm{C}$, o 1-MCP, aplicado no início do armazenamento, propiciou maior firmeza de polpa, manteve os frutos mais verdes, com maiores níveis de sólidos solúveis totais, acidez titulável e menor ocorrência de podridões. independente da reaplicação do produto.
\end{abstract}

Palavras-chave: etileno, armazenamento, pós-colheita, 1-MCP Malus domestica Borkh.

\section{ABSTRACT}

The objective of this work was to verify the efficacy of the initial application of 1-methylcyclopropene (1-MCP) and the effect of different reapplication dosis after 4 months of cold storage on quality of apple cv. Gala. The treatments originated from the combination between application time (at storage and after four months of storage) and dosis of 1-MCP $(0,312,625 n L L$ ${ }^{1}$. The treatments were: $0+O n L L^{-1} ; 0+312 n L L^{-1} ; 0+625 n L L^{-1}$;
$625+O n L L^{-1} ; 625+312 n L L^{-1}$ and $625+625 n L L^{-1}$. After 180 days of storage at $0.5^{\circ} \mathrm{C}$ and 14 days at $20^{\circ} \mathrm{C}$, the initial application of $625 n L L^{-1}$ of 1-MCP provided the highest flesh firmness, titratable acidity and maintained fruit skin greener. However, there was no effect on fruit decay and total soluble solid content. The reapplication of 1-MCP, after four months of storage, showed no effect on fruit quality. The application of 1-MCP after 14 days at $20^{\circ} \mathrm{C}$ at the beginning of the storage period, independently of the reapplication, maintained higher flesh firmness, higher levels of TSS and titratable acidity, greener skin color and lower decay incidence.

Key-words: ethylene, storage, postharvest, 1-MCP, Malus domestica Borkh.

\section{INTRODUÇÃO}

A maçã 'Gala', uma das cultivares mais produzidas no Brasil, pode ser conservada em média por três meses sob armazenamento refrigerado (AR). Após esse período, ocorrem problemas de ordem fisiológica e sanitária, que diminuem a qualidade dos frutos. A rápida perda da qualidade está relacionada com os altos índices de produção de etileno e a alta taxa respiratória dos frutos dessa cultivar (BRACKMANN, 1992).

O etileno está envolvido na aceleração do amadurecimento e senescência de frutos climatéricos. Em determinado estádio de maturação, o etileno se liga ao seu receptor na célula, um complexo protéicoenzimático, e desencadeia uma série de transformações bioquímicas que culminam com o amadurecimento e

${ }^{1}$ Engenheiro Agrônomo, Doutor, Professor do Departamento de Fitotecnia, Centro de Ciências Rurais (CCR), Universidade Federal de Santa Maria (UFSM), 97105-900, Santa Maria, RS. Autor para correspondência. E-mail: brackman@ccr.ufsm.br

${ }^{2}$ Engenheiro Agrônomo, aluno do Programa de Pós-graduação em Agronomia (PPGA), UFSM, bolsista do Conselho Nacional de Desenvolvimento Científico e Tecnológico (CNPq). E-mail: isestari@yahoo.com.br

${ }^{3}$ Engenheiro Agrônomo, MSc, Aluno do PPGA, UFSM, bolsista da Coordenação de Aperfeiçoamento de Pessoal de Nível Superior (Capes). E-mail: cristianosteffens@bol.com.br

${ }^{4}$ Acadêmico do curso de Agronomia, bolsista da Fundação de Amparo à Pesquisa do Estado do Rio Grande do Sul (FAPERGS). E-mail: hetgiehl@yahoo.com.br 
senescência do fruto (BURG \& BURG, 1967; LELIÈVRE et al., 1997a).

Nos últimos anos, várias técnicas têm sido desenvolvidas para diminuir o efeito do etileno. A atmosfera com um baixo teor de oxigênio e alto nível de gás carbônico efetivamente inibe a síntese e sua ação. O oxigênio é um dos substratos do ácido 1aminociclopropano-1-carboxílico oxidase (ACCoxidase), enzima que cataliza a conversão do ACC a etileno, enquanto o gás carbônico é considerado como um inibidor competitivo da ligação do etileno ao seu receptor. Também alguns absorvedores de etileno têm sido desenvolvidos, porém nenhum deles tem apresentado resultados totalmente satisfatórios, pois nem sempre reduzem as concentrações de etileno abaixo do nível fisiologicamente ativo.

O composto volátil 1-metilciclopropeno (1-MCP) tem demonstrado ser um potente inibidor da ação do etileno (SEREK et al., 1995). Embora seja um gás, tem sido formulado em pó, sendo liberado quando misturado a uma solução básica ou água. O 1-MCP liga-se fortemente ao sítio do etileno com uma meia vida de difusão entre 7 e 12 dias (SISLER \& BLANKENSHIP, 1996; SISLER \& SEREK, 1997). Esse tempo de difusão sugere que a ligação do 1-MCP ao receptor do etileno é irreversível. Nos estudos de eficácia, maçãs expostas ao 1-MCP por 24 horas e armazenadas a $1^{\circ} \mathrm{C}$ não responderam ao etileno por meses, porém quando armazenadas a $20^{\circ} \mathrm{C}$ responderam após 12 a 14 dias (SISLER \& SEREK, 1997). Assim, ou o complexo receptor do 1-MCP é metabolizado ou novos receptores são gerados em alta temperatura. A reaplicação de 1-MCP em baixas doses poderia, então, ser usada durante o armazenamento para prolongar o seu efeito, quando já aplicado inicialmente em baixa dose, logo após a colheita.

Estudos recentes verificaram que o 1-MCP, além de restringir a ação do etileno, pode reduzir sua produção e retardar o amadurecimento de muitos frutos climatéricos, como ameixa (ABDI et al., 1998), maçã (FAN et al., 1999), pêra (LELIÈVRE et al., 1997b), banana (SISLER \& SEREK, 1997; GOLDING et al., 1998; JIANG et al., 1999), damasco (FENG et al., 2000), abacate (FAN et al., 2000) e tomate (NAKATSUKA et al., 1997; SISLER \& SEREK,1997).

O presente trabalho teve como objetivo avaliar a eficiência da aplicação inicial de 1-MCP e o efeito de diferentes doses de reaplicação, após um período de quatro meses de armazenamento refrigerado, na manutenção da qualidade de maçãs cultivar Gala.

\section{MATERIAL E MÉTODOS}

O experimento foi conduzido no Núcleo de Pesquisa em Pós-colheita (NPP), da Universidade Federal de Santa Maria (UFSM), no ano de 2002. Foram utilizadas maçãs da cultivar Gala proveniente de um pomar comercial, pertencente à empresa Schio, localizado no município de Vacaria-RS. No momento da instalação do experimento, os frutos apresentavam os seguintes valores para os parâmetros de maturação: índice iodo-amido 8,3; firmeza de polpa $80,8 \mathrm{~N}$; acidez titulável $4,79 \mathrm{cmol} \mathrm{L}^{-1}$; sólidos solúveis totais $11,7^{\circ}$ Brix.

O delineamento experimental foi $o$ inteiramente casualizado, sendo que cada tratamento possuiu quatro repetições com unidade experimental composta de 25 frutos. Os tratamentos originaram-se da combinação de uma aplicação inicial (início do armazenamento $\left.0,0,0,625,625,625 \mathrm{nLL}^{-1}\right) \mathrm{com}$ reaplicação de diferentes doses de 1-MCP $(0,312,625$, $\left.0,312,625 \mathrm{nLL}^{-1}\right)$ após quatro meses de armazenamento.

Para o armazenamento, foram utilizadas minicâmaras experimentais de atmosfera controlada (AC), com volume de 232 litros. A temperatura foi monitorada diariamente, por meio de termômetros com precisão de $0,1^{\circ} \mathrm{C}$. A umidade relativa do ar foi de 96\%. A aplicação de 1-MCP foi realizada no início e após quatro meses de armazenamento e, como fonte de 1-MCP, utilizou-se o produto Smart Fresh ${ }^{\circledR}(0,43 \%$ de 1-MCP na formulação pó).

$\mathrm{O}$ produto foi solubilizado em $25 \mathrm{ml}$ de água a $25^{\circ} \mathrm{C}$, em um recipiente hermético, e, posteriormente, a solução foi transferida para uma placa de petri, já no interior da minicâmara, fechandose imediatamente a câmara. Os frutos ficaram expostos aos tratamentos por 24 horas a $0,5^{\circ} \mathrm{C}$ e, em seguida, as minicâmaras foram ventiladas, com o auxílio de uma bomba de ar com vazão de $14 \mathrm{~m}^{3} \mathrm{~h}^{-1}$, durante uma hora.

As análises laboratoriais foram realizadas após 180 dias de armazenamento refrigerado (AR) e após 14 dias de exposição dos frutos à temperatura de $20^{\circ} \mathrm{C}$. Os parâmetros analisados foram: firmeza de polpa, determinada com um penetrômetro com ponteira de $11 \mathrm{~mm}$ de diâmetro; acidez titulável, avaliada pela titulação de $10 \mathrm{ml}$ de suco em $100 \mathrm{ml}$ de água destilada com solução de $\mathrm{NaOH} 0,1 \mathrm{~N}$ até $\mathrm{pH}$ 8,1 ; sólidos solúveis totais ( $\mathrm{SST}$ ), determinados mediante o uso de um refratômetro, com correção da temperatura; podridões, obtidas pela percentagem de frutos que apresentavam lesões e características de ataque de fungos com diâmetro maior que $0,5 \mathrm{~cm}$ e 
degenerescência senescente, avaliada pela contagem dos frutos que apresentavam escurecimento da polpa, característico desse distúrbio fisiológico. Já para as análises de produção de etileno e da respiração dos frutos, realizadas aos 3, 6, 9 e 12 dias de exposição dos frutos a temperatura de $20^{\circ} \mathrm{C}$, após 180 dias de armazenamento refrigerado, transferiu-se aproximadamente $1200 \mathrm{~g}$ de frutos de cada repetição para recipientes de $5 \mathrm{~L}$, que foram fechados hermeticamente por aproximadamente 3 horas. Para a determinação da produção de etileno, retiraram-se duas amostras de ar de $1 \mathrm{~mL}$ do interior do recipiente e injetou-se em um cromatógrafo a gás, equipado com detector de ionização por chama (FID) e coluna Porapak N 80/100. A temperatura da coluna, injetor e detector foi de 90,140 e $200^{\circ} \mathrm{C}$, respectivamente. Calculou-se a síntese de etileno em $\mathrm{ml} \mathrm{C}_{2} \mathrm{H}_{4} \mathrm{~kg}^{-1} \mathrm{~h}^{-1}$, através da concentração de etileno, da massa dos frutos, do volume do espaço livre no recipiente e do tempo de fechamento. $\mathrm{O}$ ar do mesmo recipiente utilizado para a determinação do etileno foi circulado através de um analisador eletrônico de $\mathrm{CO}_{2}$, marca Agri-datalog. Através da concentração de $\mathrm{CO}_{2}$ presente no espaço livre do recipiente, juntamente com a determinação do volume do espaço livre, do peso dos frutos e do tempo de fechamento, foi calculada a respiração em $\mathrm{ml} \mathrm{CO} \mathrm{kg}^{-1} \mathrm{~h}^{-1}$.A cor de fundo da epiderme foi medida através de um colorímetro, marca Minolta, pelo sistema tridimensional de cores CIE $\mathrm{L}^{*} \mathrm{a} * \mathrm{~b} *$, onde, $\mathrm{a} *$ representa as cores do verde ao vermelho e $b^{*}$ representa as cores do azul ao amarelo. Os resultados foram expressos, fazendo-se o somatório do valor de $a^{*}$ e $b^{*}$.

Os resultados obtidos foram submetidos à análise de variância. Para a comparação entre médias, adotou-se o teste de Duncan em nível de 5\% de probabilidade de erro. As variáveis expressas em percentagem, foram transformadas pela fórmula $\operatorname{arc} . \operatorname{sen} \sqrt{\mathrm{x} / 100}$

\section{RESULTADOS E DISCUSSÃO}

Após 180 dias de armazenamento refrigerado a $0,5^{\circ} \mathrm{C}$, a aplicação inicial de $625 \mathrm{nLL}^{-1}$ de 1-MCP proporcionou frutos com maior firmeza de polpa (Tabela 1). Após 14 dias de exposição dos frutos à temperatura de $20^{\circ} \mathrm{C}$, a aplicação inicial de $625 \mathrm{nLL}^{-}$ ${ }^{1}$, bem como a reaplicação de 312 e $625 \mathrm{nLL}^{-1}$ de 1 MCP, determinaram, em média, melhor manutenção da firmeza de polpa (Tabela 1). Resultados similares foram obtidos em maçã (FAN et al., 1999a) e banana (JIANG et al., 1999). A maior firmeza dos frutos tratados com as maiores concentrações de 1-MCP está associada à redução da atividade das enzimas pectolíticas, devido à redução da ação do etileno (JACOMINO et al., 2002).

A acidez titulável foi superior nos frutos tratados com $625 \mathrm{nLL}^{-1}$ iniciais, embora a reaplicação aos quatro meses não tenha influenciado esta variável (Tabela 1). O mesmo comportamento foi observado na análise realizada aos 14 dias de exposição à $20^{\circ} \mathrm{C}$ (Tabela 2). FAN et al. (1999 a,b) também observaram manutenção da acidez titulável em 'Red Delicious', 'Granny Smith', 'Fuji', 'Jonagold', 'Ginger Gold' e 'Gala' com a aplicação de 1-MCP.

Os SST e a ocorrência de podridões não foram influenciados pelos tratamentos, na análise da saída da câmara (Tabelas 1 e 3). Porém aos 14 dias a $20^{\circ} \mathrm{C}$, o teor de sólidos solúveis foi maior nos tratamentos com aplicação inicial de 1-MCP (Tabela 1). Entretanto, em 'Royal Gala', a eliminação de etileno proporcionou os menores valores de SST (BRACKMANN et al., 2000). O efeito verificado aos 14 dias provavelmente seja devido ao efeito da temperatura aumentando o metabolismo e proporcionando maior acúmulo de açúcares decorrente da hidrólise de amilopectinas e pela degradação de protopectinas.

A ocorrência de podridões foi menor quando foi aplicado inicialmente $625 \mathrm{nLL}^{-1}$ de 1 -MCP, independente da reaplicação (Tabela 3). O retardo do amadurecimento dos frutos pode resultar em redução do desenvolvimento de podridões. No entanto, o 1MCP não tem efeito direto sobre fungos e, à medida que os frutos recuperam a habilidade de amadurecer, as podridões podem eventualmente se desenvolver.

A aplicação inicial de $625 \mathrm{nLL}^{-1}$ manteve os frutos mais verdes, baseado nos valores de $a^{*}$ e b*, em ambas avaliações, independente da reaplicação (Tabela 3). A retenção da coloração verde da epiderme em frutos tratados com 1-MCP também foi verificada em ameixa (ABDI et al., 1998), banana (GOLDING et al., 1998), tomate (DUPILLE \& SISLER, 1995) e abacate (Fan et al., 2000 apud BLANKENSHIP \& DOLE, 2003). A falta da ação do etileno pela ação do 1-MCP inibe a atividade das clorofilases diminuindo a degradação das clorofilas (SEREK et al., 1995).

Os tratamentos não influenciaram a ocorrência de degenerescência da polpa, na avaliação realizada aos 14 dias de exposição dos frutos a $20^{\circ} \mathrm{C}$ (Tabela 3 ). Contrariando os resultados obtidos por BRACKMANN et al. (2003), que afirmam que a ocorrência de degenerescência da polpa é menor nos frutos armazenados com remoção de etileno. Isto pode ser explicado pelo fato de que a remoção do etileno 
Tabela 1 - Firmeza de polpa, acidez titulável e sólidos solúveis totais em maçã cv. Gala após 180 dias de armazenamento refrigerado a $0,5^{\circ} \mathrm{C}$, com aplicação de 1-MCP no início do armazenamento e reaplicação após quatro meses. Santa Maria/RS, 2002.

\begin{tabular}{|c|c|c|c|c|c|c|c|c|c|}
\hline \multirow{3}{*}{$\begin{array}{c}\text { Reaplicação de } \\
\text { 1-MCP (ppb) }\end{array}$} & \multicolumn{3}{|c|}{ Firmeza de polpa $(\mathrm{N})$} & \multicolumn{3}{|c|}{ Acidez titulável $\left(\mathrm{cmol} \mathrm{L}^{-1}\right)$} & \multicolumn{3}{|c|}{ SST $\left({ }^{\circ}\right.$ Brix $)$} \\
\hline & \multicolumn{3}{|c|}{ Aplicação de 1-MCP $\left(\mathrm{nLL}^{-1}\right)$} & \multicolumn{3}{|c|}{ Aplicação de 1-MCP $\left(\mathrm{nLL}^{-1}\right)$} & \multicolumn{3}{|c|}{ Aplicação de 1-MCP $\left(\mathrm{nLL}^{-1}\right)$} \\
\hline & 0 & 625 & Média & 0 & 625 & Média & 0 & 625 & Média \\
\hline \multicolumn{10}{|c|}{ Saída da câmara após 180 dias de armazenamento refrigerado } \\
\hline 0 & 57,44 & 69,15 & $63,37 a^{1}$ & 2,31 & 3,05 & $2,71 \mathrm{a}$ & 12,13 & 12,00 & $12,06 \mathrm{a}$ \\
\hline 312 & 54.93 & 70,44 & $62,76 \mathrm{ab}$ & 2,56 & 3,03 & $2,79 \mathrm{a}$ & 12,25 & 12,10 & $12,17 \mathrm{a}$ \\
\hline 625 & 52,92 & 68,24 & $60,66 \mathrm{~b}$ & 2,56 & 3,23 & $2,89 \mathrm{a}$ & 12,00 & 12,30 & $12,15 \mathrm{a}$ \\
\hline Média & $55,17 \mathrm{~B}$ & $69,36 \mathrm{~A}$ & & $2,47 \mathrm{~B}$ & $3,12 \mathrm{~A}$ & & $12,12 \mathrm{~A}$ & $12,13 \mathrm{~A}$ & \\
\hline $\mathrm{CV}(\%)$ & \multicolumn{2}{|c|}{3,72} & & \multicolumn{3}{|c|}{8,56} & \multicolumn{2}{|c|}{3,89} & \\
\hline \multicolumn{10}{|c|}{ Após 14 dias de exposição dos frutos a $20^{\circ} \mathrm{C}$} \\
\hline 0 & 36,89 & 51,60 & $44,30 \mathrm{~b}^{1}$ & 2,08 & 2,57 & $2,32 \mathrm{a}$ & 11,80 & 12,10 & $11,95 \mathrm{a}$ \\
\hline 312 & 41,12 & 55,88 & $48,56 \mathrm{a}$ & 2,21 & 2,72 & $2,46 \mathrm{a}$ & 11,65 & 12,10 & $11,87 \mathrm{a}$ \\
\hline 625 & 39,36 & 58,32 & $48,90 \mathrm{a}$ & 1,83 & 2,79 & $2,31 \mathrm{a}$ & 11,15 & 11,85 & $11,56 \mathrm{a}$ \\
\hline Média & $39,17 \mathrm{~B}$ & $55,34 \mathrm{~A}$ & & $2,04 \mathrm{~B}$ & $2,69 \mathrm{~A}$ & & $11,53 \mathrm{~B}$ & $12,02 \mathrm{~A}$ & \\
\hline $\mathrm{CV}(\%)$ & \multicolumn{2}{|c|}{5,59} & & \multicolumn{2}{|c|}{14,85} & & \multicolumn{2}{|c|}{2,83} & \\
\hline
\end{tabular}

${ }^{1}$ Médias não seguidas pela mesma letra, minúscula na vertical e maiúscula na horizontal, diferem pelo teste de Duncan a 5\% de probabilidade de erro.

reduz a degradação dos componentes da parede celular,em especial a protopectina.

A respiração e a produção de etileno foram menores nos frutos tratados com 1-MCP, independente da reaplicação aos quatro meses de armazenamento refrigerado, nas análises realizadas aos 3, 6, 9 e 12 dias de exposição dos frutos a $20^{\circ} \mathrm{C}$ (Tabelas 2 e 4). Esse fato pode ser explicado pela redução da síntese de novos sítios receptores devido à baixa temperatura durante o armazenamento. A redução da produção de etileno e da taxa respiratória explicam a maior conservação dos frutos tratados com
1-MCP. Resultados semelhantes também foram observados por ABDI et al. (1998); GOLDING et al. (1998); FAN et al. (1999) e JIANG et al. (1999). Ao comparar-se a produção de etileno do dia $3 \mathrm{com}$ a do dia 12 , verifica-se que ocorreu um aumento de quase 20 vezes na produção (Tabela 2). Este fato provavelmente é devido à síntese de novos sítios receptores de etileno, já que o 1-MCP se liga aos receptores do etileno com uma meia vida de difusão entre 7 e 12 dias. Este tempo de difusão sugere que a ligação ao receptor é praticamente irreversível, porém, assim que o complexo receptor do 1-MCP é

Tabela 2 - Produção de etileno em maçã cv. Gala após 180 dias de armazenamento refrigerado a $0,5^{\circ} \mathrm{C}$, mais 12 dias de exposição a $20^{\circ} \mathrm{C}$, com aplicação de 1-MCP no início do armazenamento e reaplicação após quatro meses. Santa Maria/RS, 2002.

\begin{tabular}{|c|c|c|c|c|c|c|c|c|c|c|}
\hline \multirow{3}{*}{$\begin{array}{l}\text { Reaplicação } \\
\text { de } \\
1 \text {-MCP (ppb) }\end{array}$} & \multirow{2}{*}{\multicolumn{2}{|c|}{$\begin{array}{l}\text { Produção de etileno } \\
\left(\mu \mathrm{Lg}^{-1} \mathrm{~h}^{-1}\right) \\
3 \text { dias } \\
\text { Aplicação de } \\
1-\mathrm{MCP}(\mathrm{ppb} \\
\end{array}$}} & \multicolumn{2}{|c|}{$\begin{array}{l}\text { Produção de etileno } \\
\left(\mu \mathrm{Lg} \mathrm{k}^{-1} \mathrm{~h}^{-1}\right) \\
6 \text { dias }\end{array}$} & \multicolumn{3}{|c|}{$\begin{array}{l}\text { Produção de etileno } \\
\left(\mu \mathrm{L} \mathrm{kg}^{-1} \mathrm{~h}^{-1}\right) \\
9 \text { dias }\end{array}$} & \multicolumn{3}{|c|}{$\begin{array}{l}\text { Produção de etileno } \\
\left(\mu \mathrm{kg}^{-1} \mathrm{~h}^{-1}\right) \\
12 \text { dias }\end{array}$} \\
\hline & & & \multicolumn{2}{|c|}{$\begin{array}{l}\text { Aplicação de } \\
\text { MCP (ppb) }\end{array}$} & \multicolumn{3}{|c|}{$\begin{array}{l}\text { Aplicação de } \\
\text { 1-MCP (ppb) }\end{array}$} & \multicolumn{3}{|c|}{$\begin{array}{l}\text { Aplicação de } \\
\text { 1-MCP (ppb) }\end{array}$} \\
\hline & 0 & 625 & 0 & 625 & & 625 & Média & 0 & 625 & Média \\
\hline 0 & $116,50 \mathrm{a} \mathrm{A}^{1}$ & 2,23 a B & 92,04 a A & 8,64 a B & 76,24 & 24,98 & 50,61 a & 51,30 & 32,10 & $41,70 \mathrm{a}$ \\
\hline 312 & 80,52 b A & 2,25 a B & $69,52 \mathrm{~b} \mathrm{~A}$ & 6,78 a B & 66,33 & 26,85 & $46,59 \mathrm{a} b$ & 54,81 & 37,29 & $46,05 \mathrm{a}$ \\
\hline 625 & $29,64 \mathrm{c} \mathrm{A}$ & 2,59 a B & $56,53 \mathrm{c} \mathrm{A}$ & 5,73 a B & 53,72 & 23,11 & $38,41 \mathrm{~b}$ & 50,46 & 36,46 & $43,46 \mathrm{a}$ \\
\hline Média & - & - & - & - & $65,42 \mathrm{~A}$ & $24,98 \mathrm{~B}$ & & $52,19 \mathrm{~A}$ & $35,28 \mathrm{~B}$ & \\
\hline $\mathrm{CV}(\%)$ & \multicolumn{2}{|c|}{18,98} & \multicolumn{2}{|c|}{14,02} & \multicolumn{3}{|c|}{24,29} & \multicolumn{3}{|c|}{12,22} \\
\hline
\end{tabular}

${ }^{1}$ Médias não seguidas pela mesma letra, minúscula na vertical e maiúscula na horizontal, diferem pelo teste de Duncan a 5\% de probabilidade de erro. 
Tabela 3 - Ocorrência de podridões e cor de fundo da epiderme e degenerescência da polpa em maçã cv. Gala após 180 dias de armazenamento refrigerado a $0,5^{\circ} \mathrm{C}$, com aplicação de 1-MCP no início do armazenamento e reaplicação após quatro meses. Santa Maria/RS, 2002.

\begin{tabular}{|c|c|c|c|c|c|c|c|c|c|}
\hline \multirow{3}{*}{$\begin{array}{l}\text { Reaplicação de } \\
1-\mathrm{MCP}(\mathrm{ppb})\end{array}$} & \multicolumn{3}{|c|}{ Podridão $(\%)$} & \multicolumn{3}{|c|}{$\operatorname{Cor}\left(a^{*} b^{*}\right)$} & \multicolumn{3}{|c|}{ Degenerescência da Polpa (\%) } \\
\hline & \multicolumn{3}{|c|}{ Aplicação de 1-MCP (ppb) } & \multicolumn{3}{|c|}{ Aplicação de 1-MCP (ppb) } & \multicolumn{3}{|c|}{ Aplicação de 1-MCP (ppb) } \\
\hline & 0 & 625 & Média & 0 & 625 & Média & 0 & 625 & Média \\
\hline \multicolumn{10}{|c|}{ Saída da câmara após 180 dias de armazenamento refrigerado } \\
\hline 0 & 2,00 & 3,93 & $2,96 \mathrm{a}^{1}$ & 52,36 & 50,91 & $51,64 \mathrm{a}$ & $-{ }^{2}$ & - & - \\
\hline 312 & 2,00 & 3,85 & $2,92 \mathrm{a}$ & 53,25 & 49,40 & $51,32 \mathrm{a}$ & - & - & - \\
\hline 625 & 2,00 & 3,00 & $2,50 \mathrm{a}$ & 52,25 & 48,22 & $50,23 \mathrm{a}$ & - & - & - \\
\hline Média & $2,00 \mathrm{~A}$ & $3,59 \mathrm{~A}$ & & $52,62 \mathrm{~A}$ & $49,51 \mathrm{~B}$ & & - & - & - \\
\hline $\mathrm{CV}(\%)$ & \multicolumn{2}{|c|}{55,37} & & \multicolumn{2}{|c|}{4,03} & & - & - & - \\
\hline \multicolumn{10}{|c|}{ Após 14 dias de exposição dos frutos a $20^{\circ} \mathrm{C}$} \\
\hline 0 & 6,25 & 2,50 & $4,37 \mathrm{a}^{1}$ & 64,29 & 61,54 & $62,92 \mathrm{a}$ & 21,42 & 17,67 & $19,54 \mathrm{a}$ \\
\hline 312 & 4,50 & 3,00 & $3,75 \mathrm{a}$ & 63,21 & 62,22 & $62,71 \mathrm{a}$ & 12,84 & 10,24 & $11,54 \mathrm{a}$ \\
\hline 625 & 6,00 & 2,00 & $4,00 \mathrm{a}$ & 62,74 & 61,08 & $61,91 \mathrm{a}$ & 18,00 & 8,97 & $13,48 \mathrm{a}$ \\
\hline Média & $5,88 \mathrm{~A}$ & $2,50 \mathrm{~B}$ & & $63,41 \mathrm{~A}$ & $61,61 \mathrm{~B}$ & & $17,42 \mathrm{~A}$ & $12,29 \mathrm{~A}$ & \\
\hline $\mathrm{CV}(\%)$ & \multicolumn{3}{|c|}{16,40} & \multicolumn{3}{|c|}{1,96} & \multicolumn{2}{|c|}{33,26} & \\
\hline
\end{tabular}

${ }^{1}$ Médias não seguidas pela mesma letra, minúscula na vertical e maiúscula na horizontal, diferem pelo teste de Duncan a $5 \%$ de probabilidade de erro.

${ }^{2}$ Não foi observada ocorrência de degenerescência da polpa na avaliação realizada na saída da câmara.

Tabela 4 - Respiração em maçã cv. Gala após 180 dias de armazenamento refrigerado a $0,5^{\circ} \mathrm{C}$, mais 12 dias de exposição a $20^{\circ} \mathrm{C}$, com aplicação de 1-MCP no início do armazenamento e reaplicação após quatro meses. Santa Maria/RS, 2002.

\begin{tabular}{|c|c|c|c|c|c|c|c|c|c|c|c|c|}
\hline \multirow{3}{*}{$\begin{array}{l}\text { Reaplicação de } \\
\text { 1-MCP (ppb) }\end{array}$} & \multicolumn{3}{|c|}{$\begin{array}{c}\text { Respiração }\left(\mathrm{ml} \mathrm{CO}_{2} \mathrm{~kg}^{-1} \mathrm{~h}^{-1}\right) \\
3 \text { dias }\end{array}$} & \multicolumn{3}{|c|}{$\begin{array}{c}\left.\text { Respiração } \mathrm{ml} \mathrm{CO}_{2} \mathrm{~kg}^{-1} \mathrm{~h}^{-1}\right) \\
6 \text { dias }\end{array}$} & \multicolumn{3}{|c|}{$\begin{array}{c}\text { Respiração }\left(\mathrm{ml} \mathrm{CO}_{2} \mathrm{~kg}^{-1} \mathrm{~h}^{-1}\right) \\
9 \text { dias }\end{array}$} & \multicolumn{3}{|c|}{$\begin{array}{c}\text { Respiração }\left(\mathrm{ml} \mathrm{CO}_{2} \mathrm{~kg}^{-1} \mathrm{~h}^{-1}\right) \\
12 \text { dias }\end{array}$} \\
\hline & \multicolumn{3}{|c|}{ Aplicação de 1-MCP (ppb) } & \multicolumn{3}{|c|}{ Aplicação de 1-MCP (ppb) } & \multicolumn{3}{|c|}{ Aplicação de 1-MCP (ppb) } & \multicolumn{3}{|c|}{ Aplicação de 1-MCP (ppb) } \\
\hline & 0 & 625 & Média & 0 & 625 & Média & 0 & 625 & Média & 0 & 625 & Média \\
\hline 0 & 12,17 & 7,44 & $9,80 a^{1}$ & 9,04 & 5,85 & $7,44 \mathrm{a}$ & 8,74 & 4,41 & $6,57 \mathrm{a}$ & 11,57 & 10,17 & $10,87 \mathrm{a}$ \\
\hline 312 & 10,85 & 5,84 & $8,34 \mathrm{~b}$ & 7,34 & 5,56 & $6,45 \mathrm{~b}$ & 7,02 & 5,92 & $6,47 \mathrm{a}$ & 11,83 & 9,64 & $10,73 \mathrm{a}$ \\
\hline 625 & 10,25 & 6,18 & $8,21 \mathrm{~b}$ & 8,54 & 5,63 & $7,08 \mathrm{ab}$ & 8,48 & 6,91 & $7,70 \mathrm{a}$ & 11,89 & 10,33 & $11,11 \mathrm{a}$ \\
\hline Média & \multicolumn{3}{|c|}{11,09 A $6,48 \mathrm{~B}$} & \multicolumn{3}{|c|}{8,31 A $5,68 \mathrm{~B}$} & \multirow{2}{*}{\multicolumn{2}{|c|}{$\frac{5,14 \mathrm{~B}}{2660}$}} & & \multicolumn{3}{|c|}{$10,04 \mathrm{~B}$} \\
\hline$\overline{\mathrm{CV}(\%)}$ & \multicolumn{3}{|c|}{6,05} & \multicolumn{3}{|c|}{12,24} & & & 26,69 & \multicolumn{3}{|c|}{7,08} \\
\hline
\end{tabular}

${ }^{1}$ Médias não seguidas pela mesma letra, minúscula na vertical e maiúscula na horizontal, diferem pelo teste de Duncan a $5 \%$ de probabilidade de erro.

metabolizado, ou novos receptores são gerados em temperaturas mais altas, o processo de inibição da ação do etileno é revertido. Isso pode explicar a crescente retomada na produção de etileno.

\section{CONCLUSÕES}

A dose de $625 \mathrm{nLL}^{-1}$ de 1-MCP aplicada no início do armazenamento apresenta grande eficácia na manutenção da qualidade da maçã 'Gala', durante seis meses de armazenamento refrigerado e mais 14 dias de vida de prateleira. A reaplicação de
1-MCP aos quatro meses de armazenamento não traz benefícios consideráveis na conservação da maçã.

\section{REFERÊNCIAS BIBLIOGRÁFICAS}

ABDI, N. et al. Responses of climateric and supressed-climacteric plums to treatment with propylene and 1-methylcyclopropene. Postharvest Biology and Technology, Amsterdam, v.14, p.2939, 1998.

BLANKENSHIP, S.M.; DOLE, J.M. 1-Methylcyclopropene: a review. Postharvest Biology and Technology, Amsterdam, v.28, p.1-25, 2003.

Ciência Rural, v.34, n.5, set-out, 2004. 
BRACKMANN, A. Produção de etileno, $\mathrm{CO}_{2}$ e aroma de cultivares de maçã. Revista Brasileira de Fruticultura, Cruz das Almas, v.14, n.1, p.103-108,1992.

BRACKMANN, A. et al. Armazenamento de maçã 'Royal Gala' sob diferentes concentrações de etileno. Revista Brasileira de Agrociência, Pelotas, v.6, n.1, p.39-41, 2000.

BRACKMANN, A. et al. Armazenamento de maçã 'Gala' em atmosfera controlada com remoção de etileno. Ciência Rural, Santa Maria, v.33, n.4, p.647-650, 2003.

BURG, S.P.; BURG, E.A. Molecular requirements for the biological activity of ethylene. Plant Physiology, Lancaster, v.42, p.144-152, 1967.

DUPILLE, E.; SISLER, E.C. Effects of ethylene receptor antagonist on plant material. In: AIT-OUBAHOU, A.; ELOTMANI, M. (Ed). Postharvest, pathology and technolgies for horticultural commodities: recents advances. Agadir : Institute Agronomique et Veterinaire Hassan II, 1995. p.294-301.

FAN, X.; MATTHEIS, J.P.; BLANKENSHIP, S.M. Development of apple superficial scald, soft scald, core flush, and greasiness is reduced by MCP. Journal of Agricultural Food Chemistry, Washington, v.47, p.3063-3068, 1999b.

FAN, X.; BLANKENSHIP, S.M.; MATTHEIS, J.P. 1methylcyclopropene inhibits apple ripening. Journal of the American Society for Horticultural Science, Alexandria, v.124, p.690-695, 1999a.

FAN, X.; ARGENTA, L.; MATTHEIS, J.P. Inhibition of ethylene action by 1-methylcyclopropene prolongs storage life of apricots. Postharvest Biology and Technology, Amsterdam, v.20, p.135142, 2000.

FENG, X. et al. Control of ethylene responses in avocado fruit with 1-methylcyclopropene. Postharvest Biology and Technology, Amsterdam, v.20, p.143-150, 2000.
GOLDING, J.B. et al. Application of 1-MCP and propylene to identify ethylene-dependent ripening processes in mature banana fruit. Postharvest Biology and Technology, Amsterdam, v.14, p.87-98, 1998.

JACOMINO, A.P. et al. Amadurecimento e senescência de mamão com 1-metilciclopropeno. Scientia Agrícola, Piracicaba, v.59, n.2, p.303-308, 2002.

JIANG, Y.; JOYCE, D.C.; MACNISH, A.J. Extension of the shelf life of banana fruit by 1-methylcyclopropene in combination whit polyethylene bags. Postharvest Biology and Technology, Amsterdam, v.16, p.187-193, 1999.

LELIÈVRE, J.M. et al. Ethylene and fruit ripening. Physiologia Plantarum, Copenhagen, v.101, p.727-739, 1997a.

LELIÈVRE, J.M. et al. Effects of chilling on the expression of ethylene biosynthetic genes in Passe-Crassane pear (Pyrus communis L.) fruits. Plant Molecular Biology, Dordrecht, v.33, p.847-855, $1997 \mathrm{~b}$.

NAKATSUKA, A. et al. Expression and internal feedback regulation of ACC synthase and ACC oxidase genes in ripening tomato fruit. Plant and Cell Physiology, v.38, p.1110-1130, 1997.

SEREK, M.; SISLER, E.C.; REID, M.S. 1 methylcyclopropene, a movel gaseus inhibitor of ethylene action, improves the life of fruit, cut flowers and potted plants. Acta Horticulturae, Wageningen, v.394, p.337-345, 1995.

SISLER, E.C.; BLANKENSHIP, S.M. Method of counteracting an ethylene response in plants. Washington, DC, 1996. (United States patent 5518988, 1997).

SISLER, E.C.; SEREK, M. Inhibitors of ethylene response in plants at receptor level: recent development. Physiologia Plantarum, Copenhagen, v.100, p.577-582, 1997. 